\title{
In Patients We Trust: Reliability of Self-Reported Weight and Height in Nuclear Medicine Patients
}

\author{
Katrin Sabine Blum ${ }^{1,2}$, Nadine Büsch ${ }^{1}$, Thomas Beyer ${ }^{3}$, Ivo Rausch ${ }^{3}$, and Lutz Stefan Freudenberg ${ }^{1}$ \\ ${ }^{I}$ ZRN Rheinland, Center for Radiology and Nuclear Medicine, Korschenbroich, Germany; ${ }^{2}$ Department of Diagnostic and \\ Interventional Radiology, University Dusseldorf Medical Faculty, Dusseldorf, Germany; and ${ }^{3}$ QIMP Team, Center of Medical Physics \\ and Biomedical Engineering, Medical University of Vienna, Vienna, Austria
}

\begin{abstract}
The aim of the study was to assess the reliability of the selfreported weight and height of nuclear medicine patients in view of recommendations for weight-dependent tracer application for imaging and therapy. Methods: In total, 824 patients (334 men and 490 women) were asked to report their weight and height before imaging or therapy and their level of confidence. Subsequently, the weight and height of each patient were measured, and body mass index, body surface area, and lean body mass were calculated. Differences between reported and true values were compared for statistically significant differences. Results: The average patient age was $60 \pm 14$ y (range, 17-91 y). An over- or underestimation of weight by at least $10 \%$ was observed in $2 \%$ of patients, and height was overestimated by $1 \%$ by the patients. The BMI calculation was affected by incorrect self-reported values. Conclusion: Most self-reported weights and heights of nuclear medicine patients are accurate. However, since over- and underestimation of weight and height lead to incorrect body mass index, body surface area, and lean body mass values, patient weights should be measured at least for patients receiving a weight-adapted therapy or if quantification in PET/CT is needed.
\end{abstract}

Key Words: self-reported weight and height; nuclear medicine imaging and therapy; BMI; BSA; LBM

J Nucl Med Technol 2019; 47:133-136

DOI: 10.2967/jnmt.118.216317

$\mathbf{P}$ atient-specific measures, such as body weight and body height and parameters calculated therefrom (e.g., body mass index [BMI], lean body mass [LBM], and body surface area [BSA]), are important information in nuclear medicine. In diagnostic imaging procedures, body weight is frequently used to determine the injected activity (I). Further, quantitative evaluations based on SUVs rely on normalization of the injected tracer to body weight, BSA, or LBM (2-4). Also, for therapeutic applications such as targeted radionuclide therapy, these body-specific measures are often used to determine the dosage of the therapeutic compound. For example, the

\footnotetext{
Received Jun. 18, 2018; revision accepted Nov. 1, 2018.

For correspondence or reprints contact: Katrin S. Blum, ZRN Rheinland,

Center for Radiology and Nuclear Medicine, Ueberseite 88, 41352

Korschenbroich, Germany.

E-mail: k.blum@zrn-info.de

Published online Nov. 9, 2018

COPYRIGHT (C) 2019 by the Society of Nuclear Medicine and Molecular Imaging.
}

dosage of ${ }^{223} \mathrm{Ra}$-dicloride for the treatment of bone metastases is based on patient weight (5), and the dose prescription for radioembolization of hepatic malignancies using ${ }^{90} \mathrm{Y}$ microspheres is based on BSA (6). Therefore, knowledge of a patient's body weight and height is a prerequisite both to avoid over- or underdosage in nuclear medicine $(7,8)$ and to use SUVs for staging of malignancies and monitoring of therapy response (9).

However, weight assessment is often based on information provided by the patient rather than on objective measurements (10). On first examination, this approach may seem appropriate because former studies have shown a relatively good conformity between patient-reported values and the actual measured weight $(11,12)$ and BMI $(13-15)$. However, the investigated patient populations in these studies were considerably small or restricted to a single professional group, sex, or age range. Thus, these results may not be transferable to the breadth of nuclear medicine patients, which is typically relatively old and mixed. Therefore, the aim of the present study was to evaluate whether weighing and measuring the height of patients are necessary before nuclear medicine procedures to gain reliable values for body weight, BMI, BSA, and LBM.

\section{MATERIALS AND METHODS}

Between October 2017 and February 2018, all patients referred to the Nuclear Medicine Department of ZRN Rheinland and the Radiology Center of Vienna were asked to participate in this study. These included both patients undergoing diagnostic nuclear medicine imaging and patients undergoing pretherapy imaging. The local ethics committee approved this prospective study, which was performed in accordance with the Declaration of Helsinki. Written consent from all patients was obtained before enrollment in this study.

Patients were asked to report their weight and height together with their level of confidence in the reported values using an individualized form. Levels of confidence were classified as confident, less confident, or not confident. Before undergoing the imaging examination and after completing the form, all patients were asked to take off their outerwear and shoes and to stand on a standard electronic bathroom scale for weighing (My Weight XL-550; My Weight Europe). They then stood without shoes for measurement of their height with a tape measure (300-cm flexible tape measure; Uxcell).

Descriptive statistics were reported. A Student $t$ test was used to test for significant differences $(P<0.05)$ in self-reported weight and height between men and women and between 2 different age groups 
TABLE 1

Self-Reported and Measured Values and the Difference Between Them

\begin{tabular}{cccc}
\hline Parameter & Self-reported values & Measured values & Difference (\%) \\
\hline Weight $(\mathrm{kg})$ & & & $-1.6 \pm 3.0(-18.6$ to 14.7$)$ \\
Total $(n=824)$ & $78.9 \pm 17.7(37.0-161.5)$ & $80.3 \pm 18.3(34.0-161.0)$ & $-1.6 \pm 2.9(-15.4$ to 14.7$)$ \\
Female $(n=490)$ & $73.0 \pm 16.9(37.0-135.0)$ & $74.3 \pm 17.5(34.0-135.0)$ & $-1.5 \pm 3.3(-18.6$ to 4.5$)$ \\
Male $(n=334)$ & $87.5 \pm 15.2(54.5-161.5)$ & $88.9 \pm 15.9(56.0-161.0)$ & \\
Height $(\mathrm{cm})$ & & & \\
Total $(n=713)$ & $170.5 \pm 9.4(146.0-196.0)$ & $170.1 \pm 9.5(146.0-196.0)$ & $0.2 \pm 1.2(-5.0$ to 7.5$)$ \\
Female $(n=413)$ & $164.9 \pm 6.2(146.0-186.0)$ & $164.5 \pm 6.5(146.0-186.0)$ & $0.2 \pm 1.1(-5.0$ to 7.5$)$ \\
Male $(n=300)$ & $178.1 \pm 7.2(158.0-196.0)$ & $177.7 \pm 7.5(156.0-196.0)$ & $0.2 \pm 1.2(-2.3$ to 7.5$)$ \\
BMI $\left(\mathrm{kg} / \mathrm{m}^{2}\right)(n=713)$ & $27.1 \pm 5.4(14.5-50.7)$ & $27.6 \pm 5.7(14.8-52.1)$ & $-1.9 \pm 3.7(-22.0$ to 13.2$)$ \\
BSA $\left(\mathrm{m}^{2}\right)(n=713)$ & $1.9 \pm 0.2(1.3-2.7)$ & $1.9 \pm 0.2(1.2-2.7)$ & $-0.5 \pm 1.6(-9.1$ to 8.3$)$ \\
LBM $(\mathrm{kg})(n=713)$ & $54.6 \pm 10.2(31.7-82.7)$ & $54.9 \pm 10.4(28.9-84.0)$ & $-0.3 \pm 2.2(-11.2$ to 12.3$)$
\end{tabular}

Data are mean $\pm S D$, followed by range in parentheses.

( $<65 \mathrm{y}$ and $\geq 65 \mathrm{y}$ ). A potential relationship between the confidence and accuracy of self-reported weight and height was analyzed using ANOVA followed by a Tukey honestly-significant-difference test.

In addition, differences in BMI, BSA, and LBM calculated from the reported weight and height and from the measured data were assessed. For this assessment, BMI, BSA, and LBM were calculated for all patients according to the following formulas:

$$
\begin{gathered}
\text { BMI }=\frac{\text { weight }}{\text { size }^{2}}(16) \\
\text { BSA }=0.007184 \times \text { size }^{0.725} \times \text { weight }^{0.425}(17) \\
\text { LBM }(\text { male })=1.1 \times \text { weight }-128 \times\left(\frac{\text { weight }}{\text { size }}\right)^{2} \\
\text { LBM (female })=1.07 \times \text { weight }-148 \times\left(\frac{\text { weight }}{\text { size }}\right)^{2}
\end{gathered}
$$

All data were statistically analyzed with the software R (The R project for Statistical Computing).

\section{RESULTS}

In total, 857 patients were examined during this study. Of these, 824 patients (96\%), 334 men and 490 women,

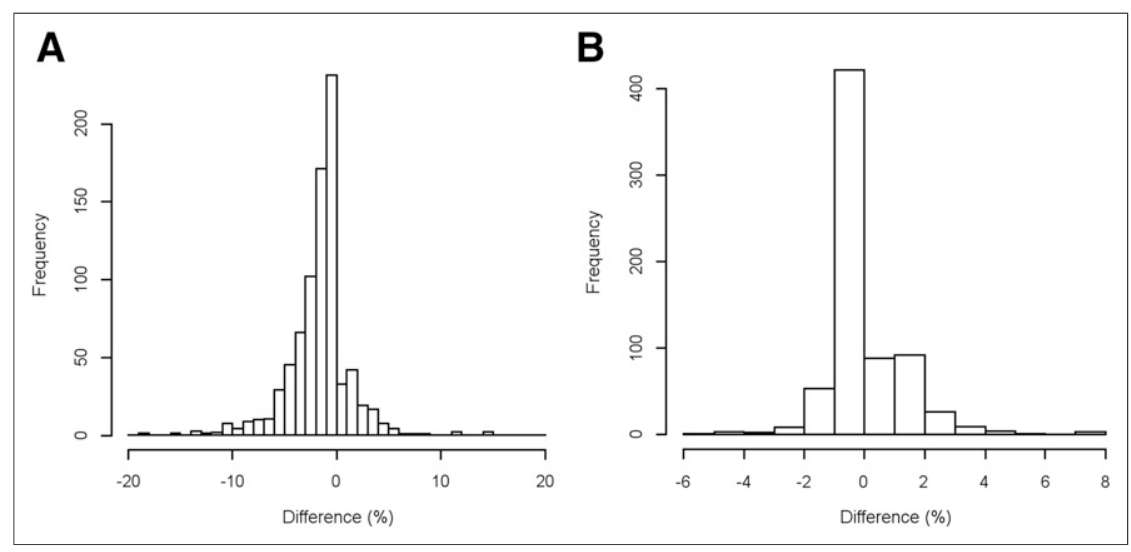

FIGURE 1. Accuracy of self-reported weight $(A)$ and height $(B)$ compared with measured weight $(A)$ and height $(B)$. agreed to participate and were included in the assessment of the reported weights. Average age was $60 \pm 14$ y (range, 17$91 \mathrm{y})$. For the assessment of the reported heights, 713 patients (300 men and 413 women) with an average age of $54 \pm 14 \mathrm{y}$ (range, 17-91 y) were included. The values of 111 patients had to be excluded from the body height assessment because they could not stand upright.

\section{Self-Reported Versus Measured Weight}

As summarized in Table 1, the mean estimated weight of all patients was $79 \pm 18 \mathrm{~kg}$ (range, 37-162 kg). The mean measured weight was slightly higher, at $80 \pm 18 \mathrm{~kg}$ (range, 34$161 \mathrm{~kg}$ ), thus indicating an underestimation of weight by 1.6 $\mathrm{kg}$ across all participants (range, 18.6-14.7 kg). A histogram of the differences between self-reported and measured weight is shown in Figure 1A, indicating that most differences ranged from $-6 \%$ to $2 \%$, with a slight tendency toward underestimation of self-reported weight. Of note, the weight was overor underestimated by more than $10 \%$ by $2.9 \%$ of the patients ( $n=18,10$ women and 8 men). However, no significant difference in the accuracy of self-reported weight was found between women and men or between different age groups. The ANOVA and Tukey test showed no significant difference in the accuracy of the reported weight between patients who were confident and patients who were less confident. However, a significant difference in the accuracy of the reported weight was found between patients who were confident or less confident and patients who were not confident (Fig. 2).

\section{Self-Reported Versus Measured Height}

The mean self-reported height was $171 \pm 9 \mathrm{~cm}$ (range, 146-196 cm), and the mean measured height was slightly less, at $170 \pm 10 \mathrm{~cm}$ (range, 146-196 $\mathrm{cm}$; Table 1). Most differences between self-reported and measured height ranged 
A

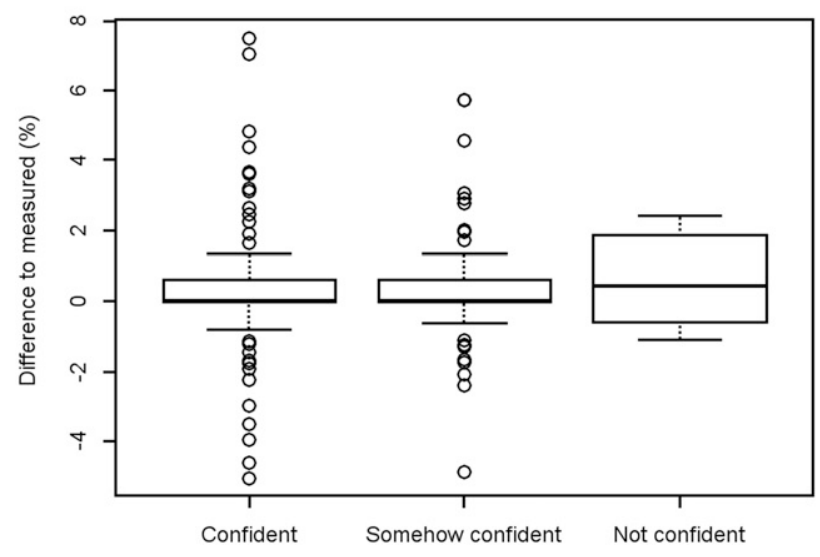

B

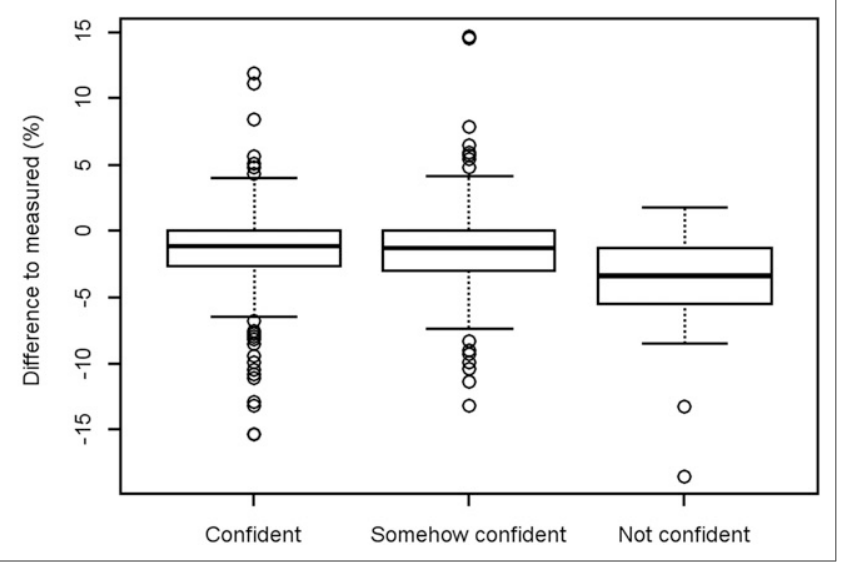

FIGURE 2. Grade of confidence in self-reported height $(A)$ and weight $(B)$ compared with difference in measured values (\%).

from $-1 \%$ to $2 \%$ in all participants (Fig. 1B). Sex and age had no significant impact on the accuracy of self-reported height. No statistical difference in the grade of confidence and accuracy regarding the reported values was found for height.

\section{BMI, BSA, and LBM}

The average deviation in the body-specific parameters calculated from the reported data was $-2 \%, 2 \%$, and $0 \%$ for BMI, BSA, and LBM, respectively. However, these deviations ranged from $-22 \%$ to $13 \%$ for $\mathrm{BMI},-9 \%$ to $8 \%$ for BSA, and $-11 \%$ to $12 \%$ for LBM. In $4 \%$ of all patients, deviations of $10 \%$ or more were found for BMI, whereas for BSA and LBM, similar deviations were present in less than only $1 \%$ of patients (Fig. 3; Table 2).

\section{DISCUSSION}

Our results show that self-reported weight and height in most adult patients in routine nuclear medicine departments are reliable, although a slight tendency toward underestimation of patient weight and overestimation of patient height was observed. Neither sex nor age had a significant impact on the validity of the reported values. The validity of the state of confidence was questionable only for the "not confident" category and, thus, not clinically significant.

In most of our patients, the difference between estimated and measured weight (average underestimation of $2 \%$ ) had no significant clinical impact. This finding is in line with previous reports for different patient groups (11-15). Similar to these studies, the percentage of under- and overestimation of weight and height was small. However, in 3\% of patients, deviations in selfreported and measured weight by more than $10 \%$ were found.

The clinical significance of this order of deviations can be manifold. For example, incorrect weight directly translates linearly into incorrect SUV calculations. Such deviations add to the bias of SUV arising from other sources and, therefore, may contribute to a bias in therapy response assessment. For therapeutic approaches, inaccuracies in body-specific measures — such as patient weight and BMI - that are used to determine the dosage may cause significant errors in individual cases. For example, in our study, the maximum deviation between declared and measured weight was $19 \%$. This would lead to a deviation of $19 \%$ from the prescribed dose if a patient were treated for metastatic castration-resistant prostate

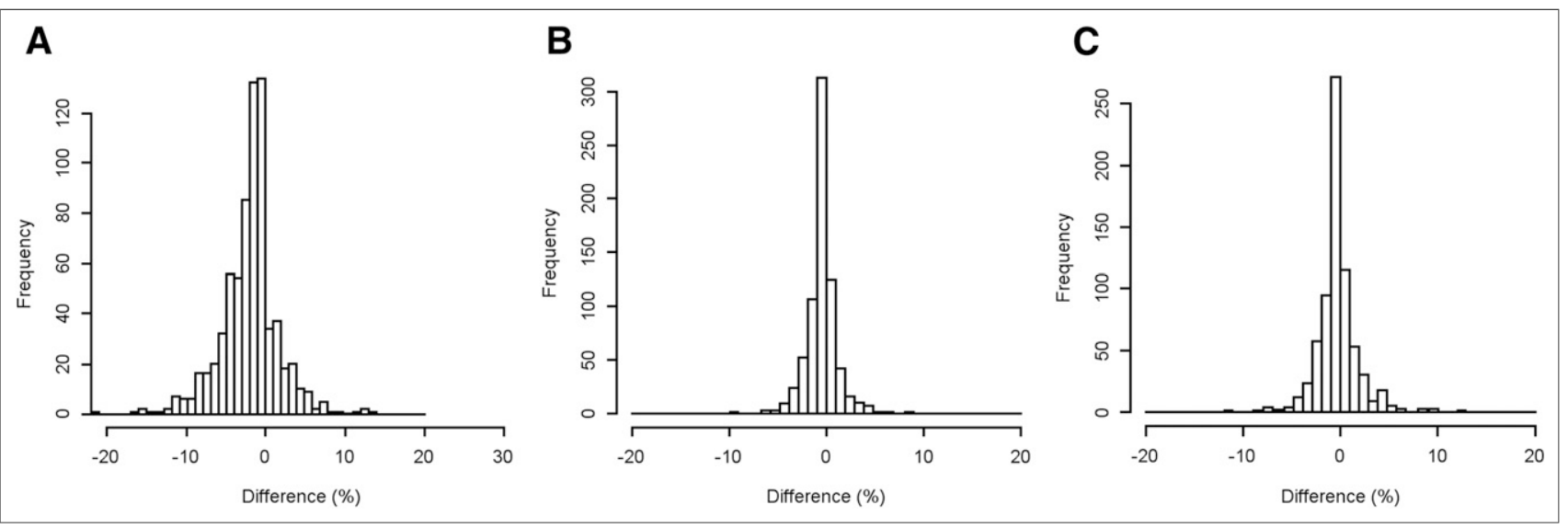

FIGURE 3. Histograms of differences between BMI (A), BSA (B), and LBM (C) calculated from self-reported and measured values. 
TABLE 2

Number of Self-Reported and Measured Values Differing by at Least $5 \%$ and $10 \%$

\begin{tabular}{lcc}
\hline Parameter & $\geq 5 \%$ difference & $\geq 10 \%$ difference \\
\hline Weight & $11 \%(91 / 824)$ & $2 \%(18 / 824)$ \\
Height & $1 \%(5 / 713)$ & $0 \%(0 / 713)$ \\
BMI & $19 \%(132 / 713)$ & $4 \%(25 / 713)$ \\
BSA & $1 \%(10 / 713)$ & $0 \%(0 / 713)$ \\
LBM & $4 \%(28 / 713)$ & $<1 \%(2 / 713)$
\end{tabular}

cancer using ${ }^{233}$ Ra-dicloride (5). Thus, this case would be regarded as a mal- or misadministration incident, which, depending on the country, would require reporting to the competent authority (e.g., in Australia the threshold for required reporting is a $15 \%$ deviation from the prescribed dose in therapeutic applications, whereas the Nuclear Regulatory Commission in the United States sets a threshold of a $20 \%$ deviation from the prescribed dose) $(19,20)$.

Because any misadministration incident is undesirable, a reliable assessment of body-specific measures used for dose calculations needs to be ensured. This holds true for values that are derived from weight and height, such as the BMI. Here, an underestimation of weight and an overestimation of height, as seen in our study, causes a multiplication of errors and, thus, may contribute to incorrect diagnostic or therapeutic decisions. For example, a 5\% underestimation of weight and a $5 \%$ overestimation of height results in a $14 \%$ underestimation of BMI. Therefore, we suggest that the measurement of all relevant parameters should be mandatory before therapy and included in the guidelines.

In general, we suggest that weight and height be measured at least for any procedure that uses these values. The time needed to measure weight and height is minor and, therefore, is not expected to influence the clinical workflow. Further, the time during these measurements can be used to interact with the patient, understand the clinical history, and get informed consent. In nuclear medicine departments where predrawn doses are used, it is necessary to ask for actual weight and height before the appointment.

A limitation of our study is that the results might be reported more accurately in the study setting than under normal circumstances. Further, it was not possible to collect height information for all patients. However, given the large sample size, adequate statistical power is expected even with the limitations mentioned above.

\section{CONCLUSION}

Our study demonstrates that although the self-reported weight and height of patients in nuclear medicine departments appear reliable in most cases, a small percentage of incorrect self-reported values would be relevant to therapeutic dosing. Therefore, we suggest that actual values, rather than self-reported values, be measured for all relevant parameters at least in patients undergoing weight-adapted therapy or a quantitative imaging procedure and in pediatric patients.

\section{DISCLOSURE}

Thomas Beyer is a cofounder and manager of cmiexperts $\mathrm{GmbH}$. He has received research funding from Siemens Healthineers. Lutz Freudenberg received speaker funding from Bayer Healthcare. No other potential conflict of interest relevant to this article was reported.

\section{ACKNOWLEDGMENT}

We thank Bärbel Beyer (Vienna), Nadine Lipzick-Dzafic (Grevenbroich), and Marita Meyer-van Egeren (Dormagen) for their help in collecting the data for this study.

\section{REFERENCES}

1. Boellaard R, Delgado-Bolton R, Oyen WJ, et al. FDG PET/CT: EANM procedure guidelines for tumour imaging: version 2.0. Eur J Nucl Med Mol Imaging. 2015;42:328-354.

2. Hoekstra CJ, Paglianiti I, Hoekstra OS, et al. Monitoring response to therapy in cancer using $\left[{ }^{18} \mathrm{~F}\right]$-2-fluoro-2-deoxy-D-glucose and positron emission tomography: an overview of different analytical methods. Eur J Nucl Med. 2000;27:731-743.

3. Thie JA. Understanding the standardized uptake value, its methods, and implications for usage. J Nucl Med. 2004;45:1431-1434.

4. Sugawara Y, Zasadny KR, Neuhoff AW, Wahl RL. Reevaluation of the standardized uptake value for FDG: variations with body weight and methods for correction. Radiology. 1999;213:521-525.

5. Poeppel TD, Handkiewicz-Junak D, Andreeff M, et al. EANM guideline for radionuclide therapy with radium-223 of metastatic castration-resistant prostate cancer. Eur J Nucl Med Mol Imaging. 2018;45:824-845.

6. Kennedy A, Nag S, Salem R, et al. Recommendations for radioembolization of hepatic malignancies using yttrium-90 microsphere brachytherapy: a consensus panel report from the radioembolization brachytherapy oncology consortium. Int J Radiat Oncol Biol Phys. 2007;68:13-23.

7. Willegaignon J, Braga LF, Sapienza MT, et al. Diagnostic reference level: an important tool for reducing radiation doses in adult and pediatric nuclear medicine procedures in Brazil. Nucl Med Commun. 2016;37:525-533.

8. Howell RW. Patient exposures and consequent risks from nuclear medicine procedures. Health Phys. 2011;100:313-317.

9. Wahl RL, Jacene H, Kasamon Y, Lodge MA. From RECIST to PERCIST: evolving considerations for PET response criteria in solid tumors. $J$ Nucl Med. 2009;50(suppl 1):122S-150S

10. Rausch I, Bergmann H, Geist B, et al. Variation of system performance, quality control standards and adherence to international FDG-PET/CT imaging guidelines: a national survey of PET/CT operations in Austria. Nuklearmedizin. 2014;53:242-248.

11. Yoong SL, Carey ML, D'Este C, Sanson-Fisher RW. Agreement between selfreported and measured weight and height collected in general practice patients: a prospective study. BMC Med Res Methodol. 2013;13:38.

12. Lin CJ, DeRoo LA, Jacobs SR, Sandler DP. Accuracy and reliability of self-reported weight and height in the Sister Study. Public Health Nutr. 2012;15:989-999.

13. Ekström S, Kull I, Nilsson S, Bergstrom A. Web-based self-reported height, weight, and body mass index among Swedish adolescents: a validation study. J Med Internet Res. 2015;17:e73.

14. Poston WS, Jitnarin N, Haddock CK, Jahnke SA, Day RS. Accuracy of self-reported weight, height and BMI in US firefighters. Occup Med (Lond). 2014;64:246-254.

15. Pursey K, Burrows TL, Stanwell P, Collins CE. How accurate is web-based selfreported height, weight, and body mass index in young adults? J Med Internet Res. 2014;16:e4.

16. Quetelet A. Recherches sur le poids de l'homme aux différens âges. SUB Göttinger Digitalisierungszentrum website. https://gdz.sub.uni-goettingen.de/id/ PPN129323640_0007?tify=\%7B\%22view\%22\%3A\%22info\%22\%2C\%22pages\% 22\%3A\%5B680\%5D\%7D. Published 1833. Accessed February 4, 2019.

17. Du Bois D, Du Bois EF. A formula to estimate the approximate surface area if height and weight be known: 1916. Nutrition. 1989;5:303-311.

18. Green B, Duffull SB. What is the best size descriptor to use for pharmacokinetic studies in the obese? Br J Clin Pharmacol. 2004;58:119-133.

19. Larcos GS, Collins LT, Georgiou A, Westbrook JI. Maladministrations in nuclear medicine: revelations from the Australian Radiation Incident Register. Med J Aust. 2014;200:37-40.

20. Subpart M: reports. U.S. Nuclear Regulatory Commission website. https://www. nrc.gov/reading-rm/doc-collections/cfr/part035/part035-3045.html. 